\title{
Financial development and macroeconomic sustainability: Modeling based on a modified environmental Kuznets curve
}

\author{
Adel Ben Youssef \\ University Côte d'Azur, France, ISEM 24, Avenue des Diables Bleus, 06300 Nice, France \\ Sabri Boubaker \\ EM Normandie Business School, Métis Lab, France \\ $\&$ \\ International School, Vietnam National University, Hanoi, Vietnam

\section{Anis Omri} \\ (Corresponding author) \\ Department of Business Administration, College of Business and Economics, Qassim University, KSA \\ E-mail address: a.omri@qu.edu.sa
}

\section{Abstract}

Sustainability has become an important and widely applied concept in the environmental economics literature. Despite the numerous studies employing an environmental Kuznets curve (EKC) this model has been critiqued for its incompleteness. This article builds a modified EKC model to examine the contribution of financial development for achieving sustainable development. Using data for 14 selected Middle East and North Africa (MENA) countries during 1990-2017, the empirical results show that the EKC hypothesis is valid for per capita $\mathrm{CO}_{2}$ emissions and ecological footprint. The results provide evidence also of the presence of linear and non-linear relationships between financial development and non-sustainability and indicate that financial development is likely to have a small long-term impact on sustainable development. This suggests that current efforts aimed at protecting the environment and achieving sustainability will be ineffective given the extent of the problem.

Keywords: Financial development; Sustainable development; Modified EKC-model 


\section{Introduction}

Meeting the sustainable development goals (SDGs) has become a global issue. It has been suggested that their achievement will require a well-developed financial sector to stimulate economic growth, determine efficient resource allocation, and contribute to protecting the environment by financing viable and environmentally friendly projects. Several studies suggest that lack of a well-developed financial sector is a major barrier to sustainable development (e.g. Painuly and Wohlgemuth, 2006; García, 2013; Kayani et al., 2020). Drawing on this research, we contribute to this debate by examining how financial development contributes to macroeconomic sustainability in the MENA countries.

The present paper has three motivations: (i) the importance of the financial sector from a sustainability perspective, (ii) the strong need for the MENA economies to achieve sustainable development, and (iii) the need for the MENA countries to accelerate their energy transition and acknowledge the importance of the financial sector in advancing economic growth and enhancing sustainability.

First, financial development is essential for promoting stable and strong economic growth (Benhabib and Spigel, 2000; Ross, 2004; Thorsten et al., Ross 2004; Federici and Caprioli, 2009). The financial sector allocates capital among economic sectors and contributes to the management of risk. It provides investors with the capital needed to invest in the production of goods and services. However, there is considerable room for financial development in the MENA countries. For instance, in Algeria and Egypt, there is a high proportion of the population that does not have a bank account and a large proportion of the financial transactions in the MENA countries are made in cash. In their approach to addressing sustainable development issues such as climate change, global warming, and environmental pollution, policymakers could exploit this potential for financial development.

Second, environmental sustainability has been high on policy agendas since 2010 . Most MENA countries signed the Paris agreement during COP 21 and need now to implement more environment-friendly policies. Taking advantage of financial development to implement such policies would be an innovative way to improve the situation in these countries. Global warming and climate change are causing natural disasters and increasing the vulnerability of this region, making greater environmental sustainability an urgent priority for the financial sector. The "greening" of the financial sector and the development of new 
financial instruments and markets to achieve sustainable development could be part of the solution to the global environmental problem. Sustainable development should become a management priority. Investment and management decisions should consider sustainability (UNEP Finance Initiative, 2007) and the modern financial industry should take into account the constraints on economic sustainability. Environmental awareness among consumers and investors in the developed economies has triggered many and rapid changes in the financial sectors of these countries. In contrast, regulation is driving the greening of the financial sector in the MENA countries. Therefore, understanding the contribution of the financial sector to achieving sustainability in the MENA region has become an urgent issue at the economic and political levels.

Finally, our study is driven by the need for the MENA countries to accelerate their energy transition and acknowledge the important role of the financial sector for advancing economic growth and enhancing sustainability. All the MENA countries have set renewable energy and energy efficiency targets. For instance, Morocco aims to reach $30 \%$ of renewables in electricity production by 2020 while Algeria has set a target of 27\% (22 GW) by 2030 (Belaïd and Youssef, 2017). Financial sector growth is correlated to this economic transformation and energy transition. Thus, it is assumed that financial development -based on an efficient banking system and availability of capital through the financial markets- will have a major impact on the speed of energy transition and the sustainability of the MENA economies. The financial sector is expected to play a key role in shaping energy transition and enhancing sustainability in the MENA countries.

This study extends the literature in several ways. First, it proposes a modified EKC model which incorporates financial development and genuine savings as a measure of sustainable development. The model examines the contribution of the financial sector to the achievement of sustainable development by the MENA countries. To the best of our knowledge, there are no empirical studies of the relationship between financial development and sustainable development. Second, the study shows that the relationship between financial development and unsustainability is non-linear i.e. initially unsustainability increases with financial development but after a given level of financial development it begins to decline. Third, among the various indicators of financial development, we use principal component analysis (PCA) to select among three indicators of financial development: M2 (broad money as a percentage of GDP), M3 (liquid liabilities as a percentage of GDP), and total credit to the private sector as a percentage of GDP. Our choice of PCA is that (i) it addresses the multicollinearity problem and the high correlation among various financial development 
indicators, and (ii) it overcomes the problem of lack of consensus on the appropriate measures of financial sector development.

The paper is organized as follows. Section 2 describes how sustainability and green growth affect financial market and investor decisions and reviews the macroeconomic literature linking financial development to sustainability. Section 3 presents the empirical methodology and section 4 summarizes and analyzes the results. Section 5 concludes with some policy implications.

\section{Finance and sustainability}

\subsection{What is green finance and sustainable finance?}

Green finance includes future-oriented financial processes, products, and services which combine environmental improvement, economic growth, and financial industry developments. Sustainable finance refers to more comprehensive and inclusive investments which take account of environmental, social, and governance aspects (Noh, 2018). Sustainable financial tools include among others, green bonds, green lending, and green equity investment. Green bonds are used to finance green projects. There are many types of green bonds including climate bonds which are related to climate change adaptation or mitigation projects (Croce, et al., 2011). In 2017, global green bonds accounted for $\$ 121.9$ billion, representing $87.1 \%$ of the world's sustainable finance market (HSBC, 2018). In addition to green bonds, banks offer green loans mostly used to finance projects aimed at protecting the environment. At the same time, investors are adopting various sustainable investment strategies such as green equity investments involving mainly equity funds and index investing (Kahlenborn et al., 2017).

Obtaining funding and raising capital in the context of the green economy requires developed financial markets. Many green economy projects are associated to high returns but should not be seen as mere commercial opportunities; they allows the financial industry to behave in a socially responsible way by contributing to the shift to a low-carbon economy and a more sustainable world. Mitigation of climate change and adaptations to reduce the effects of climate change require the participation of various organizations and sectors including financial services. In the period to 2035 some $\$ 90$ trillion of investment in sustainable infrastructure will be needed to reduce world carbon emissions (Bhattacharya et al., 2015). The United Nations Environment Program (UNEP) estimates that the transition to a low carbon world will cost $\$ 60$ trillion by 2050 with $\$ 35$ trillion going to support decarbonization of energy and the remaining $\$ 25$ trillion to supporting climate change adaptation. Additional 
investment in green sectors will be needed to advance the move towards a low carbon and climate resilient economy (Campiglio, 2016). For instance, the integration of green and sustainable finance requires financial professionals to have green finance knowledge and skills and availability of a wide range of innovative products and services especially in the insurance sector. Thus, green finance must shift from the provision of financial services to becoming a primary banking and finance provider. Environmental sustainability remains a long way off since significant funding continues to be allocated to destructive environmental activities including use of fossil fuel which has long-term catastrophic effects on climate change. Green financing and sustainability can be tackled only through the provision of significant investment in low-carbon technologies to reduce the impact of climate change.

The emergence of the green economy is providing investors with new opportunities and the possibility to identify optimal green portfolios. According to Noh (2018), green investors benefit compared to traditional investors. Firms that create green value offer better financing opportunities and the value of green investments has increased more than traditional investments. Policy efforts and opportunities for green investors should be encouraged. Green financing is important for several reasons (Noh, 2018) including the increasing risk linked to environmental degradation and reduced availability of natural resources. Firms need to deal with these risks to avoid potential economic losses. Stakeholders are requiring firms and financial agencies to be socially responsible and there is greater social awareness about climate change, exhaustion of natural resources, and environmental degradation which is promoting stricter international agreements and environmental regulation. Finally, firms' management strategies are emphasizing sustainability. Green finance has two effects (Noh, 2018), namely, (i) mitigation of environmental damage, in particular the effects of climate change on human capital and economic systems, and (ii) support for green growth. The green growth paradigm combines economic growth and environmental protection which require capital financing.

The financing of green industries will involve several problems. First, there is a high level of uncertainty related to investment in green industries whose assets tend to be more intangible. Second, green industry enterprises feature high information asymmetry (Noh, 2018). From the investor's point of view, the risks linked to sustainability and climate change incidents in recent years are a concern, and stakeholders in equity markets and credit rating agencies consider such investments and financing decision risks as non-trivial(Weber, 2014; Weber, Scholz, \& Michalik, 2010). Also, Lopez and Toman (2006) point out that failure to 
achieve sustainability is often the result of weak legal systems and financial markets, underinvestment in human and social capital, corruption, and rent seeking behavior.

\subsection{The role of financial development in decarbonization and sustainability}

The EKC literature includes analyses of the link between financial development and carbon emissions. This body of work is reviewed in detail since it is connected to the topic of our study The EKC hypothesis is based on the link between environmental degradation and income. It assumes that up to a certain level carbon emissions increase with per capita income beyond which the relationship reverses and environmental pollution starts decreasing ${ }^{1}$. Grossman and Krueger's (1991) pioneering study tests Kuznets's (1955) assumptions and their findings have become the basis of much EKC research. However, the results of these empirical studies are inconclusive (Omri et al., 2015). Some find a linear link between income growth and CO2 emissions (Shafik, 1994; Omri, 2013) while others report an N-shaped (Friedl and Getzner, 2003; Onafowora and Owoye, 2014), a U-shaped (Omri, 2018), or no relationship (Richmond and Kaufmann, 2006; Tiba and Omri, 2017). Tamazian et al. (2009) show that there are other variables that might affect environmental quality and should be included in the EKC model. They consider financial sector development to be a major contributor to sustainable development. Frankel and Romer (1999) also include financial development in the EKC function and find that improved environmental quality is sensitive to the level of financial development which attracts more foreign investment and in turn enhances economic growth and reduces environmental quality through the consumption of more energy (Islam et al., 2013). In contrast, financial development leads to use of environmentally friendly technology which decreases pollution and promotes economic growth (Omri et al., 2019).

Moreover, Steffen et al. (2015) update the great acceleration graphs and consider the joint presence of foreign direct investment, international tourism, and telecommunications as leading to increased globalization and connectivity. Primary energy use is a key indicator related directly to the carbon footprint and its effect on the functioning of the earth system; it

\footnotetext{
${ }^{1}$ Most of the EKC literature assumes weak sustainability and does not take account of irreversibility and other issues linked to "strong sustainability". Th studies in this strand of work use "CO2 emissions, $\mathrm{SO} 2$ emissions or GHG emissions in general" to proxy for environmental quality. Few papers extend the EKC framework to consider more complex indexes. In our work, despite these limitations we use Genuine savings (GS) as proxy for environmental quality (sustainability). This construct considers more environmental assets in its composition and tries to examine different facets of environmental degradation. However, the construct is still considered as a construct of a weak sustainability. These shortcomings should be considered when interpreting our results.
} 
is considered a key feature of contemporary society. Lagoarde-Segot and Martinez (2020, p. 14) consider ecological finance theory which states that "the world has entered the Anthropocene and posits that the fairness and efficacy of a financial system cannot be evaluated based on the monetary signals that it generates internally, but by examining feedbacks with the biophysical and socioeconomic spheres" . According to Nystrom (2019), it is necessary to redirect finance, increase transparency and traceability in supply chains, and involve a multitude of players in order to steer the global production ecosystem towards a sustainable trajectory.

Several works examine the financial development-environmental quality nexus but the findings are mixed . For example, Jalil and Feridn (2011) use Chinese data to investigate the effects of financial development, energy use, and income on environmental quality and find that financial sector development has no impact on reducing $\mathrm{CO}_{2}$ emissions in China. Ozturk and Acaravci (2013) employ the ARDL approach and find no significant effect of financial sector development on $\mathrm{CO} 2$ emissions although in the case of Pakistan, Javid and Sharif (2016) find a quadratic link between financial development and environmental degradation i.e. that financial development initially increases $\mathrm{CO}_{2}$ emissions but beyond a certain level of financial development, the effect becomes negative. Dar and Asif (2018) find similar results for Turkey. and Haseeb et al. (2018) analyze the effect of financial sector development on environmental quality for the BRICS economies using a standard EKC model. They show that financial development increases carbon emissions in these economies.

\subsection{The case of the MENA region countries}

Only a few studies assess the link between financial development and environmental degradation in the MENA countries. However, the effect of financial development on the environment in the countries is of concern. Arouri et al. (2012) examine the relationship between $\mathrm{CO} 2$ emissions, energy consumption, and real GDP in the MENA countries and find no confirmation of an EKC except in the case of Jordan. In almost all countries the estimated long-run coefficient of income and its square support the EKC hypothesis. However, in some cases the turning points of the EKC are very low in some cases they are very high which provides only weak support for the EKC hypothesis. Omri et al. (2015) examine 12 MENA countries using a simultaneous equation modeling approach which includes financial development in the standard EKC function. They show that financial development decreases carbon emissions only in Jordan. Omri et al. (2019) examine the non-linear link between financial development, human development, FDI, trade, and environmental sustainability in 
the case of Saudi Arabia and find that financial sector development initially increases carbon emissions but after a certain level they decline. They suggest that the level of financial development in Saudi Arabia should be boosted to a certain level to achieve a positive effect on environmental sustainability.

Charfeddine and Kahia (2019) employ a panel vector autoregressive (PVAR) model to investigate the impact of renewable energy and financial development on $\mathrm{CO}_{2}$ emissions and economic growth in 24 MENA countries. They show that renewable energy consumption and financial development have a minor influence and only explain a small part of $\mathrm{CO}_{2}$ emissions and economic growth. Their findings suggest that the financial and renewable energy sectors in MENA countries need to be strengthened to improve the contribution to economic growth and environmental quality. Gaies et al. (2019) examine the relationship between financial development and energy consumption in the MENA countries and find that financial development has positive impact on energy demand in these countries. They suggest that when modeling energy demand, financial development variables need to be included to address energy reduction and greenhouse gas emissions issues. Muhammad (2019) also finds a positive relationship between financial development and energy consumption in the MENA countries.

Ekwueme and Zoaka (2020) use FMOLS (fully modified ordinary least squares) and DOLS (dynamic ordinary least squares), to examine the influence of financial development, willingness to trade, and utilization of energy on $\mathrm{CO} 2$ emissions in the case of 10 MENA countries. Their main finding is of a negative relationship between financial development and $\mathrm{CO}_{2}$ emissions, meaning that higher levels of financial development result in reduced $\mathrm{CO}_{2}$ emissions. Nathaniel et al. (2020) employ an augmented mean group algorithm, to examine the impact on the environment of renewable and non-renewable energy consumption in the MENA countries, accounting for financial development. They suggest that urbanization, economic growth, and financial development contribute to environmental degradation in the region, pointing to the need for environmentally-friendly energy sources. Similarly, Saidi (2020) found that $\mathrm{CO}_{2}$ emissions are driven by growth, urbanization, openness to trade, and financial development.

Awan et al. (2020) investigated the impact of globalization and financial development on $\mathrm{CO}_{2}$ emissions in six MENA countries. Using panel data, they show that globalization and financial development have an adverse and significant impact on the environment. Their results also support the EKC hypothesis for the MENA countries included in their study. Yilanci and Gorus (2020) examine the impact of economic globalization on the ecological 
footprint of 14 MENA countries. Their findings indicate that financial globalization can predict the environmental degradation in MENA countries.

\section{Empirical methodology}

\subsection{Model specifications}

Critique of the standard EKC formulation has promoted intense discussion over alternatives ways to illustrate the causality between income growth and per capita $\mathrm{CO}_{2}$ emissions. For example, Tamazian et al. (2009) indicate that to avoid omitted variables bias in the econometric estimations, other variables than income, energy use, and $\mathrm{CO}_{2}$ emissions need to be included in the EKC function. Several studies include other major determinants of carbon emissions such as trade liberalization to test the "pollution haven hypothesis", (Ang, 2009; Omri et al., 2015). Other works argue that the inclusion of control variables such as the manufacturing sector, human development indicators (Ben Youssef et al., 2016), and the financial sector (Pata, 2018; Omri e al., 2019) would increase the representativeness of the EKC model.

Based on the above, we propose the following EKC function

$\mathrm{E}_{\mathrm{it}}=\alpha_{0}+\alpha_{1} \mathrm{Y}_{\mathrm{it}}+\alpha_{2} \mathrm{Y}_{\mathrm{it}}^{2}+\alpha_{3} \mathrm{EC}_{\mathrm{it}}+\alpha_{4} \mathrm{~T}_{\mathrm{it}}+\alpha_{5} \mathrm{MAN}_{\mathrm{it}}+\alpha_{6} \mathrm{MHDI}_{\mathrm{it}}+\alpha_{7} \mathrm{~F}_{\mathrm{it}}+\mu_{\mathrm{it}}$

In equation (1), we include MHDI (a modified HDI) to substitute for HDI which does not include per capita GDP. Also in excluding income, the MHDI avoids multicollinearity between the human development index (HDI) and economic growth (Y). Instead of controlling for omitted variables by including additional explanatory variables in the standard EKC model, we build a more sustainably oriented EKC model which includes financial development as an explanatory variable and as a sustainability instrument. Financial development allows investors to use advanced environmentally friendly technologies for production which improves both environmental quality and economic development (Shahbaz et al. 2013a). Financial development also has an impact on environmental degradation (Omri et al., 2015). Using data for Indonesia, Shahbaz et al. (2013b) investigate the determinants of environmental degradation and find that the link between financial development and

\footnotetext{
${ }^{2}$ Indicates that globalization (foreign direct investment and trade liberalization) increases pollution levels in host countries (Omri and Belhadj, 2020).
} 
environmental degradation takes a quadratic form. This implies that a less developed financial sector reduces environmental quality, and vice versa.

Following Shahbaz et al. (2013b), a first modification to the EKC model is given by:

$$
\mathrm{E}_{\mathrm{it}}=\alpha_{0}+\alpha_{1} \mathrm{~F}_{\mathrm{it}}+\alpha_{2} \mathrm{~F}_{\mathrm{it}}^{2}+\alpha_{3} \mathrm{Y}_{\mathrm{it}}+\alpha_{4} \mathrm{E}_{\mathrm{it}}+\alpha_{5} \mathrm{~T}_{\mathrm{it}}+\alpha_{6} \mathrm{MAN}_{\mathrm{it}}+\alpha_{7} \mathrm{MHDI}_{\mathrm{it}} 29 q_{l_{\mathrm{it}}}
$$

The linear and non-linear terms for financial development $\left(F\right.$ and $\left.F^{2}\right)$ are introduced into the model to assess the existence of an EKC between financial development and pollution. To provide a more general framework for sustainability, we (i) include a more comprehensive measure of development in the EKC model i.e. human development to replace GDP (Y) with, (ii) replace the dependent variable (E) by an economic sustainable variable (i.e. genuine saving -GS), and (iii) incorporate rule of law (RL) as a main determinant of sustainability (Ben Youssef et al., 2018).

Based on the works of Ben Youssef et al. (2018), the macroeconomic sustainable variable (GS) is described as follows

$\mathrm{GS}=\dot{\mathrm{K}}-\left(\mathrm{F}_{\mathrm{R}}-\mathrm{f}_{\mathrm{r}}\right)(\mathrm{R}-\mathrm{g})-\mathrm{b}(\mathrm{e}-\mathrm{d})$

where $\mathrm{K}, \mathrm{F}_{\mathrm{R}} \mathrm{f}_{\mathrm{r}} \mathrm{R}, \mathrm{g}, \mathrm{b}, \mathrm{e}, \mathrm{d}$ denote respectively economic capital formation, resource rental rates net of the marginal costs of extraction, resources extracted, natural growth rate for renewables, the marginal cost of abatement, pollution, and natural dissipation.

Genuine saving (GS) is based on the hypothesis of a limit and a perfect value of sustainability where

- Non-sustainability $(-G S) \rightarrow G S<0$

- Minimum level of sustainability $\rightarrow G S=0$

- Sustainability $(+G S) \rightarrow G S>0$

The quadratic link between per capita income and carbon emissions in equation 1 can be reformulated using a modified EKC to introduce the non-linear terms of financial sector development, substituting the environmental degradation-related dependent variable (E) with a negative GS (-GS) as a measure of non-sustainability, and replacing GDP by HDI. Therefore, the modified HDI is the sum of the education and life expectancy indices. Also, 
excluding GDP from the modified HDI mitigates the multicollinearity problem between GS saving and HDI.

The incorporation of additional variables in the standard $\mathrm{EKC}$ function allows the effect of financial development on sustainable development to be analyzed. Thus, the standard and modified EKC models are given respectively by equations 4 and 5

$$
\begin{aligned}
& \mathrm{E}_{\mathrm{it}}=\alpha_{0}+\alpha_{1} \mathrm{Y}_{\mathrm{it}}+\alpha_{2} \mathrm{Y}_{\mathrm{it}}^{2}+\alpha_{3} \mathrm{EC}_{\mathrm{it}}+\alpha_{4} \mathrm{~T}_{\mathrm{it}}+\alpha_{5} \mathrm{MAN}_{\mathrm{it}}+\alpha_{6} \mathrm{MHDI}_{\mathrm{it}}+\alpha_{7} \mathrm{~F}_{\mathrm{it}}+\mu_{\mathrm{it}} \\
& -\mathrm{GS}_{\mathrm{it}}=\lambda_{0}+\lambda_{1} \mathrm{~F}_{\mathrm{it}}+\lambda_{2} \mathrm{~F}_{\mathrm{it}}^{2}+\lambda_{3} \mathrm{EC}_{\mathrm{it}}+\lambda_{4} \mathrm{~T}_{\mathrm{it}}+\lambda_{5} \mathrm{MAN}_{\mathrm{it}}+\lambda_{6} \mathrm{MHDI}_{\mathrm{it}}+\lambda_{7} \mathrm{RL}_{\mathrm{it}}^{331}+\varepsilon_{\mathrm{it}} \\
& 3332
\end{aligned}
$$

where $i(i=1 \ldots N)$ is country and $t(t=1 \ldots T)$ is the time period. $\alpha_{1} \ldots, \alpha_{7}$ are the elasticities of environmental degradation with respect to GDP, squared GDP, energy use, trade, manufacturing, MHDI, and financial development respectively. In the first model, we use $\mathrm{CO}_{2}$ emissions and ecological footprintas measures of environmental degradation (E) ${ }^{4}$.

In equations 4 and 5 , the expected signs of $d \mathrm{Y} / \mathrm{dE}>0 ; \mathrm{dF} / \mathrm{dGS}>0$ and $\mathrm{dY} / \mathrm{dE}<0$; $\mathrm{dF}^{2} / \mathrm{dE}<0$ suggest a quadratic relationship between income and $\mathrm{CO}_{2}$ emissions, and financial development and sustainability. The signs of $\alpha_{3}$ and $\lambda_{3}$ are expected to be positive because more energy use results in greater economic activity and leads to more environmental pollution. The signs of $\alpha_{4}$ and $\lambda_{4}$ are expected to change depending on the stage of development. The signs of $\alpha_{5}$ and $\lambda_{5}$ are expected to be positive indicating that a higher manufacturing value added is associated to higher levels of environmental degradation andGS per capita. The sign of $\alpha_{7}$ depends a priori on the stage of development. In the early stages, the financial sector is less concerned with environmental degradation. However, once the economy matures, financial sector development benefits the environment through lending for environmentally-friendly technologies to support domestic production. This implies that a less developed (efficient) financial sector reduces (improves) environmental quality. The sign on rule of law is expected to be negative, implying that greater control over corruption reduces negative genuine saving. Finally, the presence of financial development and genuine saving in the MEKC allows assessment of the link between financial development and sustainable development.

\subsection{Data description and financial development measures}

\footnotetext{
${ }^{4}$ Most studies use $\mathrm{CO}_{2}$ emissions to measure environmental degradation but these represent a small proportion of total environmental degradation (Al-Mulali et al., 2015).
} 


\subsubsection{Data description}

To study the contribution of financial development to sustainable development using a MEKC, we analyze 14 MENA countries over 1990-2017. These countries are Algeria, Bahrain, Egypt, Iran, Jordan, Kuwait, Morocco, Oman, Qatar, Saudi Arabia, Syria, Tunisia, Turkey, and United Arab Emirates. We include $\mathrm{CO}_{2}$ emissions (C) and ecological footprint (ECL) as dependent variables to allow comparison between the standard and modified EKC.

The models include: $\mathrm{CO} 2$ emissions (C) and ecological footprint (ECL) to measure environmental degradation (E), per capita income (GDP, Y) to measure economic growth, per capita energy use (EC), per capita trade defined as total exports plus imports, manufacturing value added as a proportion of GDP (MAN), financial development (F) measured by total credit to the private sector as a proportion of GDP, per capita -GS as a measure of sustainable development, institutional quality measured by the rule of law, and MHDI measured as secondary education plus life expectancy but excluding the GDP index (Y) to avoid multicollinearity between GDP and HDI and between GDP and negative real saving (-GS). Each country's human development index is calculated as the simple arithmetic average of the ???, ???? and ???? (Sagar and Najam, 1998; UNDP, 2008). The HDI formula depends on these three indexes:

$$
H D I=\frac{1}{3} G D P+\frac{1}{3} \text { Education }+\frac{1}{3} \text { Life expectancy }
$$

Several studies modify the conventional HDI by subtracting the share of GDP. In this case, the MHDI does not include an income factor and multicollinearity remains a potential problem in the regression analysis. Costantini and Monni (2008) used a similar approach to examine the linkage between sustainable development and economic growth for 179 countries and Dhahri and Omri (2018) use it to explore the relationship between entrepreneurship and sustainable development for the case of 20 developing countries.

$$
\text { MHDI is presented as follows: } \mathrm{MHDI}=\frac{1}{2} \text { Education }+\frac{1}{2} \text { Life expectancy }
$$

Table 1 reports the source and definition of the used variables.

\section{Table 1}

\begin{tabular}{|c|c|c|}
\hline Variable & Definition & Data Source \\
\hline $\begin{array}{l}\text { Ecological footprint } \\
\text { (ECL) }\end{array}$ & $\begin{array}{l}\text { Natural logarithm of ecological footprint (gha per } \\
\text { capita). }\end{array}$ & Global Footprint Network \\
\hline $\mathrm{CO}_{2}$ emissions $(\mathrm{C})$ & Natural logarithm of $\mathrm{CO}_{2}$ emissions (tons per capita). & Word Development Indicators \\
\hline Genuine Saving (-GS) & $\begin{array}{l}\text { Natural logarithm of per capita GS (constant } 2005 \\
\text { \$). }\end{array}$ & Word Development Indicators \\
\hline GDP $(Y)$ & Natural logarithm of GDP per capita (constant $2005 \$$ ). & Word Development Indicators \\
\hline
\end{tabular}

Variables definition and data sources 


\begin{tabular}{|c|c|c|}
\hline Financial development (F) & $\begin{array}{l}\text { Natural logarithm of Board money (M2) as share of } \\
\text { GDP. } \\
\text { Natural logarithm of liquid liabilities (M3) as share of } \\
\text { GDP. } \\
\text { Natural logarithm of total credit to the private sector as a } \\
\text { share of GDP. }\end{array}$ & Word Development Indicators \\
\hline Foreign trade $(\mathrm{T})$ & $\begin{array}{l}\text { Natural logarithm of trade (imports and exports) as a } \\
\text { share of GDP }\end{array}$ & $\begin{array}{l}\text { Word Development } \\
\text { Indicators }\end{array}$ \\
\hline Energy consumption (E) & $\begin{array}{l}\text { Natural logarithm of energy use (oil equivalent per } \\
\text { capita). }\end{array}$ & $\begin{array}{l}\text { Word Development } \\
\text { Indicators }\end{array}$ \\
\hline development & $\begin{array}{l}\text { Measured by the Modified Human Development Index. } \\
\text { The MHDI measures the average achievements in a } \\
\text { country in two basic dimensions of human development } \\
\text { (Education index and Life expectancy index). }\end{array}$ & $\begin{array}{l}\text { Calculated using data from } \\
\text { World Development } \\
\text { Indicators }\end{array}$ \\
\hline Manufacture (MAN) & $\begin{array}{l}\text { Natural logarithm of manufacture value added as share } \\
\text { of GDP. }\end{array}$ & $\begin{array}{l}\text { Word Development } \\
\text { Indicators }\end{array}$ \\
\hline Institutional quality & Rule of law & $\begin{array}{l}\text { Word Development } \\
\text { Indictors }\end{array}$ \\
\hline
\end{tabular}

\subsubsection{Financial development measure: Principal component analysis}

PCA is used to select the best indicators of financial development among M2 (broad money as a share of GDP), M3 (liquid liabilities as a share of GDP), and total credit to private sector as a proportion of GDP (see e.g. Ang and McKibbin, 2007). We chose PCA because (i) it addresses the multicollinearity problem and the high correlation among the various indicators of financial development, and (ii) there is no consensus on the most appropriate measure of financial development.

The PCA results are reported in table 2. The eigenvalue related to the first component is greater than 1 (2.533). It accounts for around $84.4 \%$ of the standardized variance. The second (third) principal component explains another $13.4 \%(0.022 \%)$ of the standardized variation but with eigenvalues less than 1 . In this case, the first principal component is related to total credit to the private sector and is the best indicator of financial development.

Table 2

Results of the principal component analysis (PCA).

\begin{tabular}{llrrr}
\hline Component & Eigenvalue & Difference & Proportion & Cumulative \\
\hline 1 & 2.533 & 2.132 & 0.844 & 0.844 \\
2 & 0.401 & 0.335 & 0.134 & 0.978 \\
3 & 0.066 & - & 0.022 & 1.000 \\
\hline
\end{tabular}

\subsection{Estimation procedures}


We use a five-step empirical methodology to estimate equations 4 and 5: (i) checking cross-section dependence (CD) for residuals using various statistic tests, (ii) examining the stationary properties of our variables, (iii) testing for the presence of cointegration among the variables, (iv) estimating the long run parameters of the two models considered, and (v) examining short- and long-term causality among the variables.

\section{Empirical results and discussion}

Three CD statistical tests data (Friedman (1937); Frees (1995); Pesaran (2004, 2006, 2015) are used to check the presence of cross-section dependence in our. The results of these tests are reported in table 3 and show that the null hypothesis of cross-section independence is rejected. In this case, the first-generation panel unit root tests could produce biased results (due to size distortions) (Apergis and Payne, 2014). Thus, it is desirable to implement secondgeneration panel unit root tests (Chudik et al., 2011). Accordingly, we use a secondgeneration panel unit root test, a cross-section augmented IPS (CIPS) which accounts for the presence of cross-section dependence. Table 4 shows that at level, all the variables are nonstationary but in first differences they are all integrated, indicating that our variables are integrated at the order 1 (I(1)). Given the above results of the panel unit root tests, it is possible to investigate the existence of long-run relationships among the variables using the Westerlund (2007) panel cointegration test.Pedroni's (1999, 2004) and Kao's (1999) tests are used as robustness checks for long-run relationships among the variables. The results in table 5 confirm the existence of long-run associations among the variables in both the EKC and MEKC models. Thus, these statistical tests suggest that the variables included are cointegrated.

Table 3

Results of cross-sectional dependence (CD) tests.

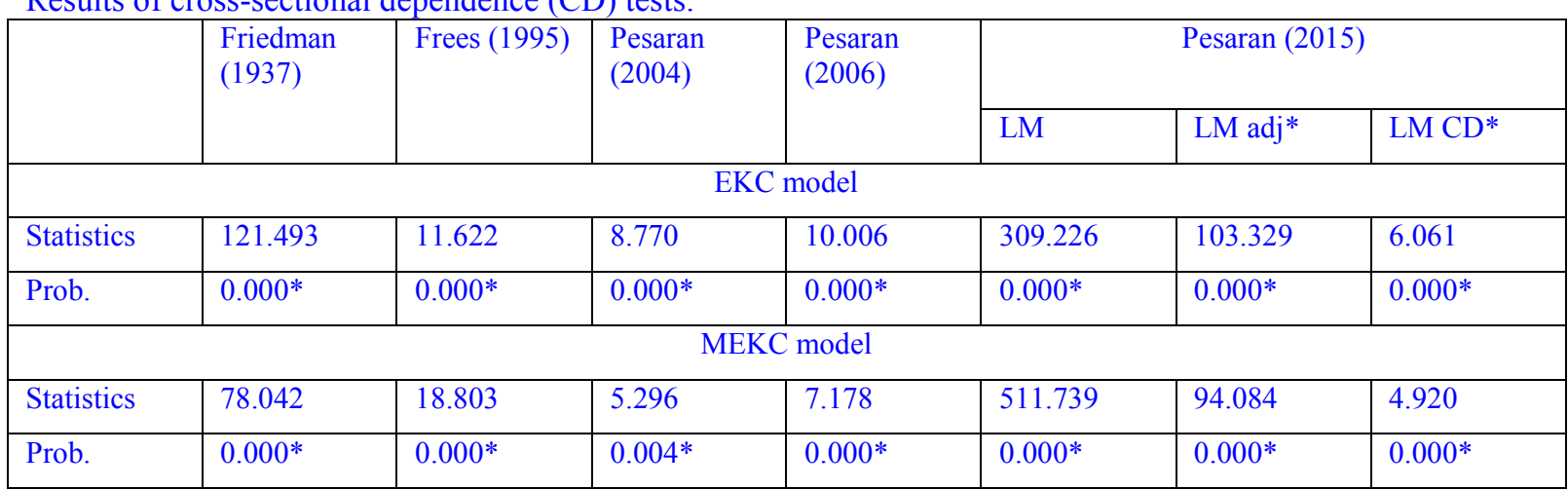

Note: The superscript * denotes statistical significance at the $1 \%$ level. Null hypothesis: Cross-sectional independence.

\section{Table 4}

CIPS unit root tests. 
431

432

433

\begin{tabular}{lcc}
\hline & \multicolumn{3}{c}{ CIPS test } & \multicolumn{1}{c}{$\Delta$} \\
\cline { 2 - 3 } Variables & Level & $-6.302^{*}[0.000]$ \\
ECL & $-0.986[1.000]$ & $-8.091^{*}[0.000]$ \\
C & $-1.299[0.822]$ & $-4.071^{*}[0.000]$ \\
Y & $-1.834[0.211]$ & $-3.990^{*}[0.000]$ \\
EC & $-0.998[1.000]$ & $-7.760^{*}[0.000]$ \\
T & $-1.189[0.902]$ & $-5.077^{*}[0.000]$ \\
MAN & $-1.660[0.452]$ & $-5.903^{*}[0.000]$ \\
MHDI & $-1.697[0.431]$ & $-4.229^{*}[0.000]$ \\
F & $-1.420[0.580]$ & $-6.039^{*}[0.000]$ \\
GS & $-1.499[0.489]$ & $-6.224^{*}[0.000]$ \\
RL & $-1.541[0.476]$ &
\end{tabular}

Note: The superscript * and $* *$ denote statistical significance at the $1 \%$ and $5 \%$ levels, respectively.

\section{Table 5}

Results of panel cointegration tests.

I-Westerlund (2007) panel cointegration test EKC model

MEKC model

\begin{tabular}{lllllllll} 
& Value & Z-value & P-value & Robust P-value & Value & Z-value & P-value & Robust P-value \\
\cline { 2 - 8 } $\mathrm{Gt}$ & -2.113 & 1.102 & 0.922 & 0.544 & $-2.691^{* *}$ & -4.006 & 0.036 & 0.018 \\
$\mathrm{Ga}$ & $-8.426^{*}$ & 2.447 & 0.004 & 0.000 & $-5.280^{*}$ & -3.995 & 0.000 & 0.000 \\
$\mathrm{Pt}$ & $-10.622^{*}$ & -4.148 & 0.000 & 0.000 & $-18.047^{*}$ & -8.201 & 0.000 & 0.000 \\
$\mathrm{~Pa}$ & $-13.079^{*}$ & -3.368 & 0.000 & 0.000 & $-12.814^{*}$ & -9.577 & 0.000 & 0.000 \\
\hline
\end{tabular}

II- Pedroni (1999, 2004) panel cointegration test

EKC model

MEKC model

Within-dimension

Panel v-stat

Panel rho-stat

Panel ADF-stat

Panel PP-stat

Between-dimension

Group rho-stat

Group ADF-stat

Group PP-stat

\begin{tabular}{ccl}
\hline t-statistics & Prob. & Within-dimension \\
\hline$-3.812^{*}$ & 0.000 & Panel v-stat \\
$-5.009^{*}$ & 0.000 & Panel rho-stat \\
$-6.798^{*}$ & 0.000 & Panel ADF-stat \\
$-2.840^{*}$ & 0.000 & $\begin{array}{l}\text { Panel PP-stat } \\
\text { Between-dimension }\end{array}$ \\
$-5.219^{*}$ & 0.000 & Group rho-stat \\
$-4.2194^{*}$ & 0.000 & Group ADF-stat \\
$-2.446^{*}$ & 0.000 & Group PP-stat
\end{tabular}

0.000

III- Kao's (1999) panel cointegration test

$$
\text { EKC model }
$$

\begin{tabular}{|c|c|}
\hline T-statistics & Prob. \\
\hline$-7.587^{*}$ & {$[0.000]$} \\
\hline
\end{tabular}

ADF

\begin{tabular}{ccc}
\cline { 2 - 3 } T-statistics & Prob. \\
\hline$-6.011^{*}$ & {$[0.000]$}
\end{tabular}

ADF

$-7.587 * \quad[0.000]$

n 5 levels, respectively. Null hypothesis: No cointegration.

436

437

438

439

440

441

442

443

444

445

446

447

Table 6 presents the results of the long-run estimates of equations (4) and (5). The results of the EKC model show that economic growth has a positive effect on both $\mathrm{CO}_{2}$ emissions and ecological footprint. The respective values 0.209 and 0.417 indicate that a $1 \%$ rise in economic growth raises carbon emissions and ecological footprint by $0.21 \%$ and $0.42 \%$; thus, an increase in economic growth is expected to lead to an increase in carbon emissions. However, the coefficient of income squared is negative and significant for both environmental variables. The positive (negative) effects of per capita income (and its square) support the EKC hypothesis that environmental degradation initially increases but then begins to decrease as per capita income goes above a certain level which confirms Omri et al.'s (2015) findings for the MENA countries and Paramati et al.'s (2018) results for Vietnam. 
Table 6 shows also that financial development contributes positively to per capita carbon emissions and per capita ecological footprint. A $1 \%$ rise in total credit to the private sector raises per capita $\mathrm{CO}_{2}$ emissions and ecological footprint by around $0.22 \%$ and $0.18 \%$, respectively. This finding contrasts with the results in Tamazian et al. (2009) that higher levels of financial development in the BRICS economies reduces environmental degradation. However, it supports the results in Zhang et al. (2011) that bank loans help Chinese companies to access external finance and enhances their investment levels, hence improving economic growth and environmental quality. The negative effect of financial sector development on carbon emissions in the MENA region suggests that a well-developed financial sector leads to lower $\mathrm{CO}_{2}$ emissions and a reduced ecological footprint. Therefore, financial development could reduce carbons emissions by providing incentives for firms to use advanced-environmentally-friendly technologies in their production processes (Ben Youssef et al., 2018). A stable financial system which allows adoption of new technologies should improve environmental quality although this might not apply in periods of economic and financial instability. Governments in the MENA region need to balance improving environmental quality with development of their financial sectors.

We show also that energy use has the expected positive and significant impact on the two indicators of environmental degradation. A $1 \%$ increase in the use of energy increases carbon emissions and ecological footprint by around $0.32 \%$ and $0.28 \%$ respectively. The findings for the other control variables show that international trade and manufacturing valueadded contribute positively to carbon emissions and ecological footprint, confirming the findings in Tiba and Omri (2015) for less developed countries which show that trade liberalization is accompanied by higher levels of environmental degradation due to delocalization of polluting industries and the pollution haven effect (Costantini and Monni, 2008).

One of the objectives of this study was to examine the effectiveness of financial development for achieving sustainable development. The MEKC estimates show that financial development increases unsustainability (-GS). The coefficient of financial development shows that a $1 \%$ increase in financial sector development increases -GS by $0.34 \%$. However, the square of financial development reduces unsustainability (-GS). These positive and negative impacts of financial development show a quadratic relationship between financial development and -GS, meaning that initially non-sustainability increases with financial development up to a certain level after which it starts to reduce -GS and increase sustainability. Despite the non-linear link between non-sustainability and development of the 
482 financial sector, since the financial sector coefficient $(F)$ is superior to its squared value $\left(\mathrm{F}^{2}\right)$, 483 an increase in financial development is likely to have only a small long-term impact on sustainable development. Hence, given the scale of the problem there is no expectation that current sustainable development efforts will be very effective. Many of the MENA economies have large reserves of natural resources whose deployment does not contribute to sustainability. We found also that foreign trade and rule of law decrease -GS by around $0.19 \%$ and $0.04 \%$, respectively similar to the findings in Costantini and Monni (2008).

Table 6 presents the short- and long-run Granger causality results for the EKC and MEKC models. The coefficients of the error correction term (ECT) are significant which is evidence of a stable long-run relationship among the variables. For the lagged ECT, we find a long-run relationship among the variables considered in both models. The results show that all the coefficients are statistically significant, and that there is bidirectional causality among most of our considered variables.

Table 5

Long-run estimates for EKC and MEKC models.

\begin{tabular}{|c|c|c|c|c|c|c|}
\hline \multirow{3}{*}{$\begin{array}{l}\text { Independent } \\
\text { variables }\end{array}$} & \multicolumn{4}{|c|}{ EKC model } & \multicolumn{2}{|c|}{ MEKC model } \\
\hline & \multicolumn{2}{|c|}{ 'C' as dependent variable } & \multicolumn{2}{|c|}{ 'ECL' as dependent variable } & \multicolumn{2}{|c|}{ '-GS' as dependent variable } \\
\hline & Coef. & Prob. & Coef. & Prob. & Coef. & Prob. \\
\hline Y & $0.209 *$ & {$[0.000]$} & $0.417 *$ & {$[0.000]$} & - & - \\
\hline $\mathrm{Y}^{2}$ & $-0.109 * *$ & {$[0.024]$} & $-0.188^{*}$ & {$[0.000]$} & - & - \\
\hline $\mathrm{F}$ & $0.223^{*}$ & {$[0.000]$} & $0.180^{*}$ & {$[0.000]$} & $0.196^{*}$ & {$[0.000]$} \\
\hline $\mathrm{F}^{2}$ & - & - & - & - & $-0.098 * *$ & {$[0.033]$} \\
\hline $\mathrm{EC}$ & $0.322 *$ & {$[0.000]$} & $0.282 *$ & {$[0.002]$} & $0.210^{*}$ & {$[0.009]$} \\
\hline $\mathrm{T}$ & 0.097 & {$[0.321]$} & -0.109 & {$[0.231]$} & $-0.185^{*}$ & {$[0.000]$} \\
\hline MAN & $0.219^{*}$ & [0.006] & $0.199 *$ & {$[0.000]$} & 0.099 & [0.217] \\
\hline MHDI & $0.107 * *$ & {$[0.000]$} & $0.098 *$ & {$[0.008]$} & $0.129 * *$ & {$[0.043]$} \\
\hline $\mathrm{RL}$ & - & - & - & - & $-0.077 * *$ & {$[0.022]$} \\
\hline Constant & $-11.602 *$ & {$[0.000]$} & $-8.281^{*}$ & {$[0.000]$} & $-7.109 *$ & {$[0.000]$} \\
\hline
\end{tabular}

Notes: $\mathrm{P}-$ values are reported in brackets. $\mathrm{C}$ and $\mathrm{ECL}$ denote per capita $\mathrm{CO}_{2}$ emissions and per capita ecological footprint, respectively. The superscripts $*$ and $* *$ denote statistical significance at the $1 \%$ and $5 \%$ levels, respectively.

The results of the standard and the modified EKC show that per capita GDP, financial development, energy use, manufacturing, trade, and human development have significant causal impacts on $\mathrm{CO}_{2}$ emissions and ecological footprint. In addition, in both models the ECT is statistically significant, indicating that the speed of adjustment of all the variables to the long-run equilibrium is relatively slow.

We found short and long-term causality among most of the variables considered in the models, and a significant ECT for the remaining variables. These relationships suggest some general implications related to the sustainability process. First, in line with work on the standard EKC, achieving a sufficient level of sustainability with a positive effect of financial 
510 development is difficult in the initial stages of economic development. Financial system 511 development is a crucial condition for achieving this goal. However, the modified EKC shows 512 that it is possible to invert and reduce non-sustainable growth in the mid term phases of 513 economic development. Second, financial development facilitates achievement and 514 maintenance of higher levels of future sustainable development . The positive impact of 515 financial development is much higher than the negative impact of natural resources 516 endowments. The resources curse can be nullified by appropriate financial system 517 development with positive effects on sustainability and environmental quality. Third, higher 518 quality institutions promote higher sustainable development. An economy with higher 519 resources exploitation combined with poor institutions is expected to experience rent-seeking 520 or Dutch disease effects resulting in reduced economic growth, and therefore, low levels of 521 financial and human development (Ben Youssef et al., 2018). Excessive resources 522 exploitation in the initial stages of development, associated to lower development of the 523 financial system and poor institutional quality is expected to lead to non-sustainable 524 development. 
Table 6

538 Results of causality test.

\begin{tabular}{|c|c|c|c|c|c|c|c|c|c|c|}
\hline \multicolumn{2}{|c|}{ Dependent variables } & \multicolumn{8}{|c|}{ Short-run sources of causation (independent variables) } & \multirow{2}{*}{$\begin{array}{l}\text { Long-run } \\
\text { ECT }\end{array}$} \\
\hline \multicolumn{2}{|c|}{ EKC model } & $\Delta \mathbf{C}$ & $\triangle \mathrm{ECL}$ & $\begin{array}{c}\Delta \mathbf{Y}\left(\Delta \mathbf{Y}^{2}\right) \\
0.994^{*}[0.000]\end{array}$ & $\Delta \mathbf{E C}$ & $\Delta \mathbf{T}$ & $\triangle \mathbf{M A N}$ & $\triangle$ MHDI & $\Delta \mathbf{F}$ & \\
\hline$\Delta \mathbf{E}$ & $\Delta \mathbf{E C L}$ & - & - & $0.691^{*}[0.000]$ & $0.278^{*}[0.000]$ & $0.197^{* *}[0.030]$ & $0.591^{*}[0.000]$ & $0.206^{*}[0.000]$ & $0.196^{* *}[0.014]$ & $-0.213^{* *}[0.010]$ \\
\hline \multicolumn{2}{|c|}{$\Delta \mathbf{Y}\left(\Delta \mathbf{Y}^{2}\right)$} & $0.198^{*}[0.000]$ & $0.189^{* *}[0.013]$ & - & $0.521^{* *}[0.021]$ & $1.902^{*}[0.000]$ & $0.428^{*}[0.000]$ & $0.321^{* *}[0.026]$ & $0.778^{*}[0.000]$ & $-0.052^{* *}[0.030]$ \\
\hline \multicolumn{2}{|c|}{$\Delta \mathbf{E C}$} & $0.160[0.211]$ & $\begin{array}{ll}0.098 & {[0.302]}\end{array}$ & $0.237^{* *}[0.040]$ & - & $0.093[0.271]$ & $1.046^{*}[0.000]$ & $0.079[0.111]$ & $0.527^{*}[0.000]$ & $-0.229^{*}[0.000]$ \\
\hline \multicolumn{2}{|c|}{$\triangle \mathbf{M A N}$} & $0.288^{* *}[0.000]$ & $0.179^{* *}[0.020]$ & $0.665^{*}[0.000]$ & $0.429^{*}[0.000]$ & $0.991^{*}[0.000]$ & - & $0.309^{*}[0.000]$ & $0.129^{*}[0.006]$ & $-0.179^{* *}[0.011]$ \\
\hline \multicolumn{2}{|c|}{$\Delta$ MHDI } & $0.430^{*}[0.000]$ & $0.222^{*}[0.000]$ & $0.771^{*}[0.000]$ & $0.155^{* * *}[0.082]$ & $0.370^{* * *}[0.052]$ & $0.176[0.120]$ & - & $0.289^{*}[0.000]$ & $-0.290^{*}[0.000]$ \\
\hline \multicolumn{2}{|c|}{$\Delta \mathbf{F}$} & $0.920^{*}[0.000]$ & $1.955^{*}[0.000]$ & $1.089^{*}[0.000]$ & $0.118[0.227]$ & $0.280^{*}[0.000]$ & $0.440^{*}[0.000]$ & $0.339^{*}[0.000]$ & - & $-0.196^{*}[0.000]$ \\
\hline \multicolumn{2}{|c|}{ MEKC model } & $\Delta$ (-GS) & $\Delta \mathbf{F}\left(\Delta \mathbf{F}^{2}\right)$ & $\Delta \mathbf{E C}$ & $\Delta \mathbf{T}$ & $\Delta$ MAN & $\Delta$ MHDI & $\overline{\Delta \mathbf{R L}}$ & & ECT \\
\hline \multicolumn{2}{|c|}{$\Delta(-\mathbf{G S})$} & - & $2.981^{*}[0.000]$ & $0.542^{*}[0.000]$ & $0.922^{*}[0.000]$ & $1.019^{*} \quad[0.000]$ & $1.156^{*}[0.000]$ & $0.472^{*}[0.000]$ & $-1.508^{* *}$ & {$[0.018]$} \\
\hline \multicolumn{2}{|c|}{$\Delta \mathbf{F}\left(\Delta \mathbf{F}^{2}\right)$} & $0.319^{*}[0.000]$ & - & $0.339^{*}[0.000]$ & $0.356^{*}[0.000]$ & $0.218^{* * *}[0.017]$ & $0.312^{*}[0.001]$ & $0.801^{*} \quad[0.000]$ & $-3.978^{*}$ & {$[0.000]$} \\
\hline \multicolumn{2}{|c|}{$\Delta$ MHDI } & $0.224^{* *}[0.017]$ & $0.331^{* *}[0.012]$ & $0.176[0.154]$ & $0.587^{*}[0.000]$ & $0.544^{*} \quad[0.000]$ & - & $0.609^{*}[0.000]$ & $-2.509^{*}$ & {$[0.000]$} \\
\hline \multicolumn{2}{|c|}{$\Delta \mathbf{R L}$} & $0.415^{*}[0.000]$ & $0.438^{*}[0.000]$ & $0.078[0.364]$ & $0.433^{*}[0.000]$ & $\begin{array}{ll}0.210 & {[0.135]}\end{array}$ & $0.470^{*} \quad[0.000]$ & - & $-3.008^{*}$ & {$[0.000]$} \\
\hline
\end{tabular}




\section{Concluding remarks and policy implications}

Although the relationship between financial sector development and environmental quality has been analyzed in the EKC literature little attention has been paid to its impact on sustainable development. The lack of empirical work on this issue was the motivation for our proposed modified EKC model which integrates both financial development and macroeconomic sustainability and allows examination of the impact of the financial sector on sustainable development in the case of 14 selected MENA countries during 1990-2017.

Our findings show (i) the validity of the EKC hypothesis for both per capita $\mathrm{CO}_{2}$ emissions and ecological footprint, (ii) the presence of a non-linear link between per capita financial development and the two indicators of environmental degradation i.e. the level of environmental degradation initially increases with financial sector development but after a certain level becomes positive as more energy-efficient technologies and more efficient infrastructures are implemented in the country's development process. Our findings show also that despite the non-linear link between unsustainability and financial sector development, the larger coefficient of financial sector development compared to its squared value indicates that financial development is likely to have only a small long-term impact on sustainable development. Therefore, current efforts aimed at protecting the environment and achieving sustainability are expected to be ineffective given the extent of the problem.

Our paper has several implications for policy in the MENA region in particular and in developing countries more general.

First, an efficient financial sector increases the amount of capital available to investors, provides economic agents with liquidity, and allocates capital more efficiently among economic sectors. Financial sector development would help MENA countries transform their economies and move to a post-oil era.

Second, the ethics and values of financial sectors worldwide are changing and the environment is being seen as an opportunity rather than a constraint. Green financing provides funding for investors who want to invest in green sectors and is encouraging traditional sectors to reduce their carbon emissions. By helping to diffuse these new values worldwide a developed financial sector could promote the move to less polluting economies. Since most MENA region financial organizations have branches in other parts of the world and belong to multinationals with social and environmental responsibility programs the diffusion of these values and good practices should be ensured. Social and environmental responsibility programs are encouraging new behaviors in the MENA region and helping local entrepreneurs 
to see the environment as offering green opportunities in their sectors. Governments in the MENA region must encourage their financial sectors to improve economic and ecological conditions by including provisions related to government loans and warranties, and interest rates for responsible environmental and social investments.

Third, the financial sector could play a crucial role in persuading investors to consider environmental and ecological sectors, such as recycling, sanitation, water, water purification, and renewable energies. Many MENA region entrepreneurs are failing to recognize the opportunities offered by climate change and consumers' increased environmental awareness. For example, most MENA countries have important oil and gas resources and therefore, are neglecting the potential of green energies especially solar. It has been estimated that installing solar panels on just $20 \%$ of the surface of the Sahara desert in Algeria could satisfy world demand for electricity. Algeria's solar energy potential is 60 times that of current European Union electricity consumption (Bélaïd and Abderrahmani, 2013). Financial sectors working with governments could help firms to exploit these sectors and reduce the risks for newborn firms. Policy makers in the MENA countries should see their financial sectors as part of the solution and should involve them in the definition of environmental policies, targets, and strategies.

Fourth, the ongoing economic, social, and ecological crisis calls for a reconsideration of the relationship between economic growth, finance, and sustainability (Lagoarde-Segot, 2015). Strengthening financial sectors and changing their focus from brown to green goals could have an important impact on environmental change in the MENA countries where most financial markets are under-developed.

This study has some limitations. The first is related to the sustainable development indicator. A transition from the Millennium Development Goals to the 17 SDGs will require different indicators related for example to food security, well-being, education quality, climate change, and pollution mitigation, among others. Future work should focus on defining these indicators. Second, this study analyzes only the direct effect of financial development on sustainability. Future research could extend this by examining policy thresholds and critical masses at which renewable energy could achieve the environmental, social, and economic objectives of sustainable development simultaneously. 